\title{
INTENSITY SETTER FOR A DEVICE OF SMOOTH START OF SUBMERSIBLE PUMP ELECTRIC MOTOR
}

Purpose. Development of an intensity setter, which in a rational law changes the opening thyristor the voltage regulator and effectively to changing power supply voltage stator windings of the electric pump deepening, ensuring a smooth start in a wide range. Methodology. Electric submersible pump belongs to the small inertia electric, since it is not significant total moment of inertia, not exceeding two moments of inertia of the motor and static moment on the shaft does not exceed forty percent of the nominal torque. For technical requirements that electric acceleration time should have no less than twenty seconds or more. Office starting modes of electric submersible pumps economically justified using thyristor voltage regulator by forming the dial changes the intensity of the necessary legislation in time voltage feeding the stator windings. This ensures a smooth start right rotor of the electric submersible pump. Results. A block diagram of the intensity setter that is: with control unit, two units that form the exponential voltage supply emitter follower and regulatory elements. The mathematical expressions for voltage at the stator windings of the motor, changing exponentially, opening the angle of thyristor power unit thyristor the voltage regulator, which is determined through the initial angle of opening. Provided formula for pick-up voltage and minimum voltage, time constants, which are determined from the basic equations of motion and mechanical characteristics of the electric motor. Analytical investigated by the voltage dependence violation by changing the time constant flowing and growing exhibitor supply voltage stator electric circuit deepening pump. Originality. Proposed in the initial time on the stator windings of the electric pick-up voltage is applied. Under the influence of this voltage, motor rotor begins to accelerate. At the same time, pick-up voltage decreases the minimum startup voltage varies exponentially in which the rotor of the electric motor continues to rotate more steadily. Now the voltage at the motor stator windings increases exponentially to the nominal voltage of the supply network. This start flowing smoothly for the right time to establish nominal rotor speed of the motor. Practical value. Developed dial allows you to increase the intensity of the electric motor acceleration time and reduce the dynamic loads of the electric submersible pump. References 9 , tables 1, figures 2 .

Key words: submersible pump, induction motor, thyristor voltage regulator, opening angle of thyristor, intensity setter, startup, acceleration time.

Рассматривается задача построения задатчика интенсивности для формирования изменения угла открывания тиристоров регулятора напряжения. Это позволяет менять по сложной траектории напряжение питания на статоре электродвигателя погружного насоса, обеспечивая, тем самым, нужное время плавного ускорения вращения ротора. Для реализации задатчика интенсивности аппаратными средствами автоматизации представлена блок-схема, а программным путем - математические выражения. Библ. 9, табл. 1, рис. 2.

Ключевые слова: погружной насос, асинхронный электродвигатель, тиристорный регулятор напряжения, угол открывания тиристоров, задатчик интенсивности, пуск, время ускорения.

Introduction. The growth of both residential and industrial construction in recent years has made steady and quality supply one of the priorities. The most promising way is to use its underground water sources via wells of varying depth, which is a complex hydraulic structure that requires a skilled approach to construction and reliable equipment - borehole pumps. These units are specifically designed to work in rather difficult conditions. They are expensive and, because of the specific installation, repair them connected with considerable difficulties and costs. Therefore, when selecting such equipment should pay attention to detail and a number of practical points to help extend the smooth operation of the equipment and minimize operating costs.

One of these key parameters - a way to start an induction electric submersible pump (IESP), which is one of the most negative modes for the electric motor and water-lifting pipe and water supply part of the well. The electric pump in this period briefly exposed to peak, so it inrush current of 4.7 times the nominal value at a rela- tively low starting point. This leads to increased wear thermal insulation of stator windings, which greatly depends on the reliability and durability of the motor. Noxious a launch for the unit and the well as a whole, as is often accompanied by a hammer that breaks pipeline valves and pump itself. The most effective solution to all these problems is to ensure smooth start IESP.

Analysis of investigations and publications. Create and start the study of controlled AC motors are widely covered in domestic and foreign literature. Generally, for this purpose, the following ways: switching scheme of «star» in the scheme «triangle» or the inclusion of the electric motor via a starting transformer or by phase control voltage on the stator or the use of frequency converters [1-9]. In practice for IESP economically feasible is a relatively simple device parametric phase control. It uses thyristor voltage regulators (TVR), which is the most widespread, their operation will be used in the future for electric low and medium power $[1-3,6,8]$.

(c) V.I. Lobov, K.V. Lobova 
Control starting modes of electric drives using TVR most simply perform by creating necessary laws intensity dial changes the time pressure that feeds the stator winding. Applied to the stator supply voltage regulating by means of open angle $\alpha_{s}$ thyristors TVR included in the stator electric circuits. Running start on a constant or continuous (linear or exponential in law) changing angles $\alpha_{s}$, formed via hardware or software setters of intensity. When the static load on the shaft of the mechanism can not regulate a wide range of time starter motor, thereby reducing starting currents and electromagnetic shock value points $[2,3,6,7]$. However, the known laws regulating angle $\alpha_{s}$ not allowed to perform controlled start IESP, the technical requirements that need to have time to disperse at least $20 \mathrm{~s}$ or more. IESP refers to small inertia drives, since it is not significant total moment of inertia $J_{\Sigma} \leq 2 J_{e}$, ( $J_{e}$ is the motor moment of inertia) and static torque on the shaft $M_{s} \leq 0.4 M_{n}\left(M_{n}\right.$ is the rated moment). Therefore, at the start of the IESP methods known enough moving voltage $U_{s}$, to electric overclocked to speeds close to par. This launch is not controlled and executed by a time equal to $0.4-0.8 \mathrm{~s}$ and is not regulated in time. Further increase in the nominal voltage does not significantly impact on the smooth start-up, as the motor speed changes in a small range $[8,9]$.

The aim of the work is the theoretical study, development and implementation of controlled smooth start asynchronous electric submersible pump when used TVR with dials of intensity, which in a rational law will change the angle of opening thyristors that will effectively influence the supply voltage stator windings of the electric motor to provide a wide range of time smooth start and extend the smooth operation of hydraulic structures and minimize operating costs.

Results of investigations. Smooth start of IESP is performed in the following manner. At the initial time in the stator winding electric voltage is applied start $U_{s}$. Under the influence of this voltage motor rotor begins to accelerate. At the same time, the voltage decreases $U_{s}$ moving during the start $\mathrm{t} 1$ exponentially to the minimum voltage $U_{\mathrm{min}}$. At this voltage motor rotor has steadily continued to rotate. Since at time $t_{1}$ and achieve a minimum voltage $U_{\min }$, the voltage at the motor stator windings increases exponentially to the nominal voltage of the supply network $U_{s n}$. This start flowing smoothly at the right time $t_{2}$ to establish nominal rotor speed of the motor.

To implement this method of launching hardware device used by intensity setter block diagram of which is given in Fig. 1.

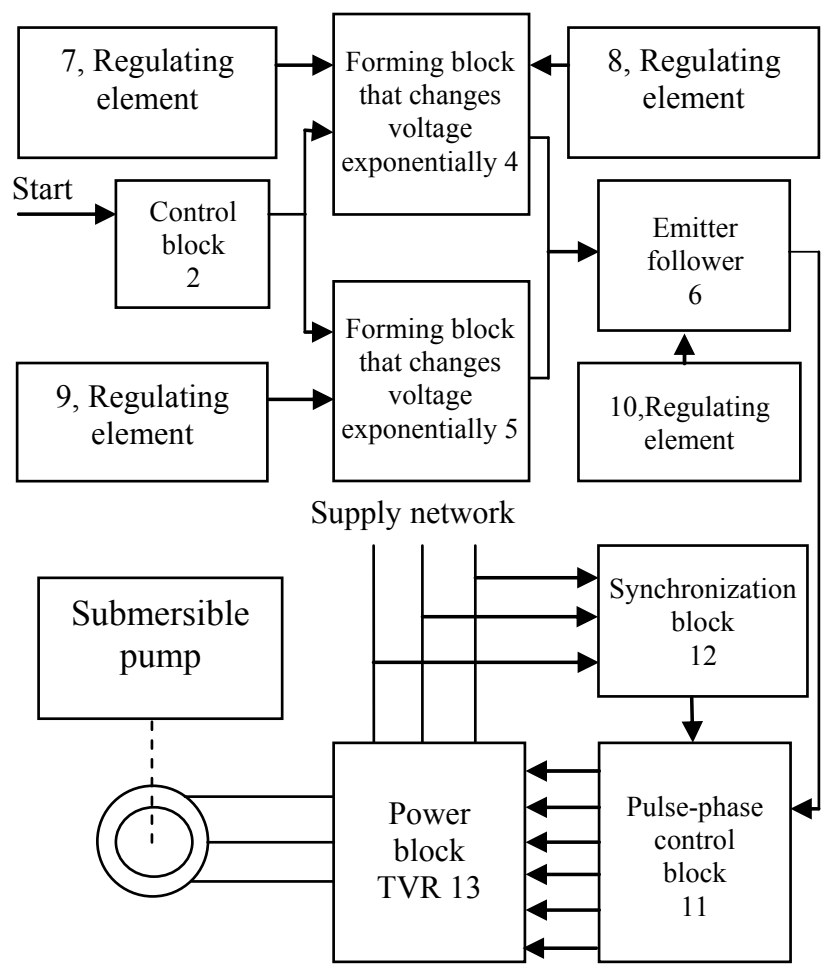

Fig. 1. The block diagram of the intensity setter for smooth start for motor type IESP

When implementing this method by software the following mathematical expression is used:

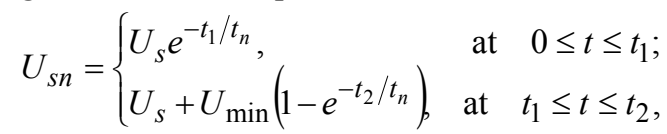

where $t_{1}, t_{2}$ are the time constants, $t_{n}$ is the total time of the IESP start.

Opening angle of thyristors of the power block of the TVR is determined by the initial angle of opening $\alpha_{(0)}$ :

$$
\alpha_{s}=\left\{\begin{array}{lll}
\alpha_{(0)}\left(1-e^{-t_{1} / t_{n}}\right), & \text { at } & 0 \leq t \leq t_{1} ; \\
\alpha_{(0)} e^{-t_{2} / t_{n}}, & \text { at } & t_{1} \leq t \leq t_{2} .
\end{array}\right.
$$

The voltage of moving and minimum voltage in expression (1), respectively, are determined by formulae:

$$
\begin{gathered}
U_{s}=U_{s n} \frac{\sqrt{M_{s}^{0}}}{M_{n}}, \\
U_{\min }=U_{s n} \frac{\sqrt{M_{s}^{1}}}{M^{s}},
\end{gathered}
$$

where $M_{s}^{0}$ is the static torque at a fixed electrical motor rotor motor; $M_{n}$ is the electrical motor starting torque at the rated supply voltage; $M_{s}^{1}$ is the static loading torque at a minimum rotor speed of an electric motor; $M^{5}$ is the torque of the electrical motor at the rated voltage and the minimum rotor speed of the electrical motor.

Time constant $t_{1}$ in expressions (1) and (2) is determined from the basic equation of motion of the electric motor and mechanical characteristics: 


$$
t_{1} \approx J_{\Sigma} \omega_{r}^{s} \ln \left|\frac{\left(M_{\alpha}+M_{s}^{0}\right) \omega_{\min }-M_{s}^{0} \omega_{r}^{s}}{M_{s}^{0} \omega_{r}^{s}}\right|,
$$

where $J_{\Sigma}$ is the superficial electric moment of inertia of electric drive; $\omega_{r}^{S}, \omega_{\min }$ are the synchronous and minimum rotor speed of the electric motor; $M_{\alpha}$ is the electromagnetic torque, determined by the mechanical characteristics of the electric motor.

Substituting numerical data gives the value $t_{1}$ (5), not exceeding five periods of the mains voltage and calculated for a specific drive. Became time $t_{2}$ in the same expressions (1) and (2) is chosen within one or two values specified time launch. This is because the voltage is sufficient to disperse IESP in the area of operating speeds, defines smooth start-up, significantly below the nominal voltage is calculated from the parameters of a particular drive. Therefore, increasing the acceleration time IESP in the area of operating speeds, it is necessary to increase the daily time $t_{2}$.

The Table gives values and Fig. $2-$ depending $U_{s}=$ $f\left(t / t_{n}\right)$ by changing the time constants $t_{1}, t_{2}$ and voltage $U_{s}$, which was calculated by the expression (1). Charts voltage $U_{s}$ are a fraction of nominal voltage $U_{s n}$ and the current time - a fraction of time in direct starting asynchronous machine with a nominal voltage and $T_{s s}$ - between the supply voltage change network $U_{s n}$.

From the results obtained it follows that increasing the time constant t 2 from 5 to $25 T_{s s}$ the minimum voltage $U_{\min }$ on the stator of the electric motor reaches a value equal $0.3 U_{s n}$ (Fig. 2,a). Increasing the time constant $t_{2}$ of values required time $t_{n}$ of the start of the electric drive to a value equal $10 t_{n}$ leads to the fact that this stress significantly reduced and reaches a value equal $0.05 U_{s n}$.

Table

Dependences $U_{s} / U_{s n}=f\left(t / t_{n}\right)$

\begin{tabular}{|c|c|c|c|c|}
\hline $\begin{array}{c}\text { Characteristic No. } \\
\text { (Fig. 2,a) }\end{array}$ & $t_{l}$ & $t_{2}$ & $\begin{array}{c}\text { Characteristic No. } \\
\text { (Fig. 2,b) }\end{array}$ & $U_{s}$ \\
\hline 1 & $5 t_{n}$ & $25 T_{s s}$ & 1 & 0.85 \\
\hline 2 & $5 t_{n}$ & $5 T_{s s}$ & 2 & 0.65 \\
\hline 3 & $5 t_{n}$ & $12,5 T_{s s}$ & 3 & 0.5 \\
\hline 4 & $t_{n}$ & $5 T_{s s}$ & & \\
\hline 5 & $3 t_{n}$ & $5 T_{s s}$ & & \\
\hline 6 & $10 t_{n}$ & $5 T_{s s}$ & & \\
\hline
\end{tabular}
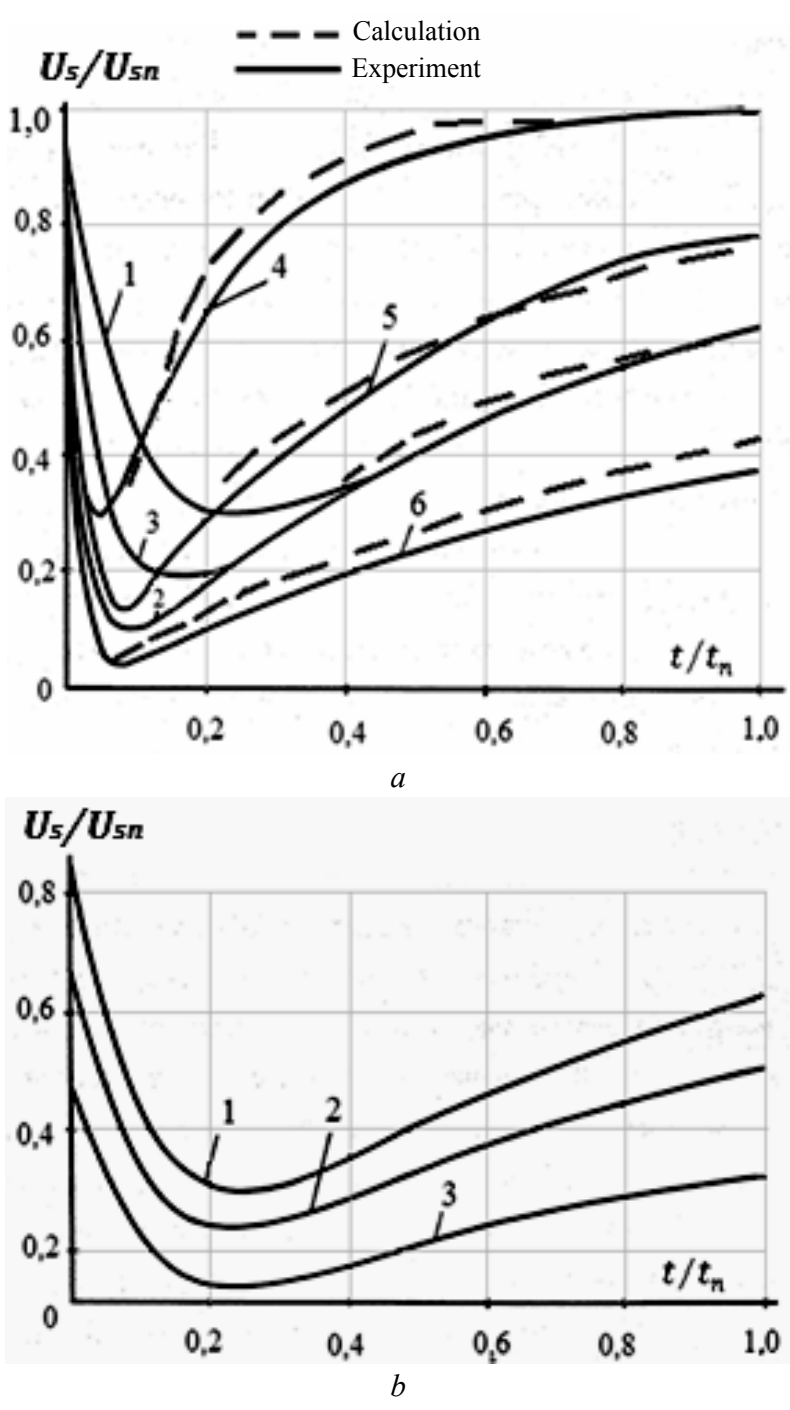

Fig. 2. Dependences $U_{s} / U_{s n}=f\left(t / t_{n}\right)$

As the $U_{s}$ decrease to $0.5 U_{s n}$ (Fig. 2,b, the third curve) this function for a time equal to $t / t_{n}=1$ reaches a value equal $0.35 U_{s} / U_{s n}$ at $U_{s}=0.8 U_{s n}$ (the second curve) $0.43 U_{s} / U_{s n}-0.43$ (Fig. 2,b). At the same time at $U_{s} / U_{s n}$ (the first curve) function has already reached the value of 0.62 . Reducing voltage $U_{s}$ leads to longer rise of the function $U_{s} / U_{s n}=f\left(t / t_{n}\right)$.

\section{Conclusions.}

1. The necessity of using a wide range of acceleration time of rotor induction motor TVR submersible pump with dial intensity, which has two time constants that vary exponentially and takes into account the magnitude of the voltage moving of the motor rotor is proved. If you change a designed dial intensity constant voltage value of time and moving of the rotor turns the family characteristics of feeding pressure from TVR which could be given to stator windings to form the starting modes asynchronous electric submersible pump and extend the smooth operation of hydraulic structures and minimize operating costs.

2. Developed intensity setter can be used to form the frequency converter starting modes used, for example, in electric drives of conveyor machines for burning pellets. 


\section{REFERENCES}

1. Lobov V.I., Lobova K.V. Method of determining the start time of induction motors in the control of resistor-thyristor modules. Elektrotekhnika i elektromekhanika - Electrical engineering \& electromechanics, 2015, no.4, pp. 40-44. (Rus). doi: 10.20998/2074-272X.2015.4.07.

2. Petrushin V.S., Yakimets A.M., Bangula V.B. Analysis of a thyristor voltage converter fed induction motor start. Elektrotekhnika i elektromekhanika - Electrical engineering \& electromechanics, 2012, no.6, pp. 31-33. (Rus). doi: 10.20998/2074272X.2012.6.06.

3. Braslavskiy I.Ya., Ishmatov Z.S., Polyakov V.N. Energosberegayushchiy asinkhronnyy elektroprivod [Energy-saving asynchronous electric]. Moscow, Academiya Publ., 2004. 256 p. (Rus).

4. Figaro B.I., Vasilyev D.S. Application of squirrel-cage induction motor soft starting and braking in the electric drives of crane travel mechanisms. Elektrotekhnichni ta kompiuterni systemy - Electrotechnic and computer systems, 2011, no.4, pp. 3038. (Rus).

5. Lobov V., Lobova K. Choice of braking method of asynchronous electric motor for using in electric drives of conveyor equipment. Metallurgical and Mining Industry, 2015, no.8, pp. 6-12.

6. Lobov V. Method for research of parametric control schemes by asynchronous motor. Metallurgical and Mining Industry, 2015, no.6, pp. 102-108.
7. Chernyi A.P., Gladyr A.I., Osadchuk Y.G. Puskovye sistemy nereguliruemykh elektroprivodov: Monografiia [Starting unregulated electric system: Monograph]. Kremenchuk: PP Cherbatyh A.V. Publ., 2006. 280 p. (Rus).

8. Lobov V.I. Issledovanie puskovykh i tormoznykh rezhimov asinkhronnykh elektroprivodov s tiristornym parametricheskim upravleniem. Diss. kand. techn. nauk [Research of starting and braking modes of asynchronous electric drives with thyristor parametric-hydraulic control. Cand. tech. sci. diss.]. Moscow, 1983. 269 p. (Rus).

9. Brodsky Y.A., Egorova S.A., Lobov V.I., Shvets S.A. Sposob puska maloinertsionnogo asinkhronnogo elektrodvigatelia [Method of starting a fast-response induction motor]. USSR Certificate of Authorship, no.1108589, 1984. (Rus).

Received 10.02.2016

V.I. Lobov ${ }^{1}$, Candidate of Technical Science,

K.V. Lobova ${ }^{1}$, student,

SIHE «Kryvyi Rih National University»,

11, XXII Partz'izdu Str., Kryvyi Rih, 50027, Ukraine, phone +380 5644090635 ,

e-mail: lobov.vjcheslav@yandex.ru

How to cite this article:

Lobov V.I., Lobova K.V. Intensity setter for a device of smooth start of submersible pump electric motor. Electrical engineering \& electromechanics, 2016, no.3, pp. 36-39. doi: 10.20998/2074-272X.2016.3.06. 